\title{
Incidental Learning of Collocation
}

\author{
Stuart Webb \\ Victoria University of Wellington \\ Jonathan Newton \\ Victoria University of Wellington \\ Anna Chang \\ Hsing-Wu University
}

This study investigated the effects of repetition on the learning of collocation. Taiwanese university students learning English as a foreign language simultaneously read and listened to one of four versions of a modified graded reader that included different numbers of encounters $(1,5,10$, and 15 encounters) with a set of 18 target collocations. A surprise vocabulary test that was made up of four tests measuring receptive and productive knowledge of the form of the target collocations and receptive and productive knowledge of the form and meaning of these collocations was administered after the treatments. The results showed that (a) collocations can be learned incidentally through reading while listening to a graded reader and (b) the number of encounters has a positive effect on learning. If learners encounter collocations 15 times within a graded reader, sizeable learning gains may occur.

Keywords incidental vocabulary learning; collocation; repetition; frequency effects; graded readers; EFL

\section{Introduction}

The majority of first language (L1) words are learned incidentally. Although there is some debate about the extent of second language (L2) incidental vocabulary learning (see Cobb, 2007; Laufer, 2001, 2003), researchers agree that

\footnotetext{
We wish to thank Frank Boers, Victoria University of Wellington, for his helpful comments on an earlier draft of this article and the anonymous reviewers for their useful comments.

Correspondence concerning this article should be addressed to Stuart Webb, Victoria University of Wellington, P.O. Box 600, Wellington 6012, New Zealand. Internet: stuart.webb@vuw.ac.nz
} 
incidental vocabulary learning should be a part of any L2 vocabulary learning program (Hunt \& Beglar, 2005; Laufer, 2001, 2003; Nation, 2001, 2008; Nation \& Webb, 2011; Schmitt, 2000, 2008; Webb \& Chang, 2012). Research on incidental vocabulary learning has shown that words are gradually learned through repeated encounters in context; the more often unknown words are encountered, the more likely they are to be learned (Chen \& Truscott, 2010; Horst, Cobb, \& Meara, 1998; Jenkins, Stein, \& Wysocki, 1984; Rott, 1999; Saragi, Nation, \& Meister, 1978; Waring \& Takaki, 2003; Webb, 2007). This line of research has focused exclusively on single-word items. However, research indicates that a large proportion of language is made up of multiword units. For instance, Hill (2001) reported that up to $70 \%$ of language is made up of fixed expressions, with the number of collocations far outnumbering the number of single-word items. Similarly, Erman and Warren (2000) found that $58.6 \%$ of spoken discourse and $52.3 \%$ of written discourse consisted of multiword combinations, and Foster (2001) found that $32.3 \%$ of spoken discourse was made up of formulaic language.

Relatively little is known about how collocations are learned. Research has shown that collocations can be learned effectively through explicit teaching (Boers, Demecheleer, \& Eyckmans, 2004; Chan \& Liou, 2005; Laufer \& Girsai, 2008; Lindstromberg \& Boers, 2008b; Sun \& Wang, 2003; Webb \& Kagimoto, $2009,2011)$. However, to our knowledge there has been little published research on incidental learning of collocation through meaning-focused input. In order to shed light on this issue, this study investigates the extent to which collocations may be learned through repeated encounters in a graded reader. Specifically, it looks at the number of encounters $(1,5,10,15)$ necessary to learn the written form and the form and meaning of collocations through reading while listening to a modified graded reader.

\section{Background}

\section{Defining Collocation}

In this study, collocation will be defined from a statistical standpoint (Greenbaum, 1974; Hunston, 2002; Partington, 1998; Sinclair, 1991) and refers to the regular co-occurrence of words within a given span demonstrating a statistical strength of co-occurrence. This definition has been widely accepted within the field of corpus linguistics (Halliday, 1966; McEnery \& Wilson, 2001; Sinclair, 1991). Statistical strength of occurrence is indicated by measures such as mutual information scores, $t$ scores, and log-likelihood, which indicate that two words occur more frequently together than would be expected by chance 
alone. The advantage of defining collocation from a statistical standpoint is that researchers can use these measures to quickly identify collocates for a word. For example, a search for nouns that occur immediately after the item gain within the British National Corpus (BNC) reveals that access, control, entry, experience, confidence, support, power, and weight all have mutual information scores indicating that they co-occur immediately after gain far more than could be expected. This provides very useful information for researchers, teachers, and learners.

Using above-chance co-occurrence as the sole criterion leads to the inclusion of idioms as collocations (Wouden, 1997). Hence, collocations used in this study include those that are likely to be experienced as highly transparent collocations such as short distance and play football, less transparent collocations such as rock (the) boat and play (it) safe, and semantically opaque collocations such as red herring and shoot (the) breeze. The disadvantage of this approach is that it does not take into consideration semantic factors that may affect the ease with which the items may be learned such as concreteness of meaning (Walker \& Hulme, 1999), transparency of meaning (Fernando, 1996; Moon, 1998; Nesselhauf, 2003), L1 and L2 congruence (Nesselhauf, 2003), and function (Forsberg, 2010). For this reason, some researchers prefer to distinguish idioms from collocations by virtue of their different degrees of semantic transparency (Fernando, 1996; Moon, 1998; Nesselhauf, 2003). However, the inclusive approach to identifying collocations we take in the current study has the advantage of eliminating a subjective component in the design that can lead to varying interpretations between studies of what is and what is not a collocation. This approach is also more ecologically valid, because in incidental learning contexts, learners are likely to encounter multiword items of varying degrees of semantic transparency. ${ }^{1}$

\section{Knowledge of Collocations in an $\mathrm{L2}$}

With increased research on vocabulary in the last three decades, there has also been increased interest in the nature and behavior of collocation (Kennedy, 2003; Liu, 2010; Mel'cuk, 1998; Moon, 1997, 1998; Nesselhauf, 2003; Stubbs, 1995; Wouden, 1997). Learner corpus-based research has indicated that L2 learners recognize and use fewer collocations (Granger, 1998) but make greater use of the collocations that they know than L1 learners (Cobb, 2003). Classroom-based research has indicated that L2 learners' knowledge of the form and meaning of collocations is less than that of single-word items (Bahns \& Eldaw, 1993), and a lack of knowledge of collocation may be responsible for a large proportion of learner errors in language production (Bahns \& 
Eldaw, 1993; Gabrys-Biskup, 1992; Hussein, 1990; Nesselhauf, 2003). The few studies investigating the learning of collocation have focused on explicit learning rather than incidental learning (Chan \& Liou, 2005; Lindstromberg \& Boers, 2008b; Sun \& Wang, 2003; Webb \& Kagimoto, 2009, 2011). This line of research has shown that collocations can be learned effectively using glossed sentences and cloze tasks (Webb \& Kagimoto, 2009), concordancers (Chan \& Liou, 2005; Sun \& Wang, 2003), contrastive analysis and translation (Laufer \& Girsai, 2008), a cognitive linguistics approach using imagery (Boers et al., 2004), and by exploiting sound patterns such as alliteration (Lindstromberg \& Boers, 2008b).

In a study that has strong implications for incidental learning of collocation, Durrant and Schmitt (2010) found that the number of sentences read aloud by participants that included targeted adjective-noun collocations had an effect on learning the form of the collocations. Scores were significantly higher when participants read aloud two sentences than when they only read aloud one sentence. Because the variable examined was exposure and the participants were unaware that they would be tested for collocational learning, the findings indicate that repetition may have an effect on learning collocations incidentally in the same way that it does for single-word items. However, the highly controlled and explicit nature of the treatment does not allow generalizability to the effects of repetition on learning from meaning-focused tasks.

\section{Methodological Issues in the Study of L2 Collocational Learning}

There are two reasons for the lack of research on incidental learning of collocation. First, despite the frequency of the individual items that make up collocations, most collocations do not occur very often; they are always less frequent than the most frequent word within the collocations. For example, in the collocation lose touch both lose and touch are found in the most frequent 1,000 word families in Nation's (2004) BNC lists. However, both of these items are used with a large number of different words. This means that each item might be encountered many times before it is encountered with the other item. For example, some other common collocates of lose are weight, contact, sight, and control while close, finishing, light, personal, and final are other frequent collocates of touch. So although each item is a high-frequency word, the collocation is encountered far less frequently with greater intervals between encounters. The lower frequency of encounters with collocations in relation to their parts increases the likelihood that knowledge gained through each encounter might be forgotten and that knowledge of the parts is likely to be greater than that of the collocations (Bahns \& Eldaw, 1993). 
In studies examining the frequency of multiword items, Martinez and Schmitt (2012) identified 505 phrasal expressions with sufficient frequency to be included in the most frequent 5,000 word families of the BNC, and Shin and Nation (2008) found that 84 collocations were frequent enough to be included within the most frequent 1,000 word types and 224 collocations were frequent enough to be included within the second most frequent 1,000 word types. The most frequent three collocations they found in the 10-million-word spoken section of the BNC were you know (27,348 occurrences), I think (that) (25,862 occurrences), and $a$ bit (2,766 occurrences). The frequency of collocations also varied between spoken and written discourse. In a comparison between the most frequent collocations in spoken and written text in the BNC, collocations were typically $50 \%$ to $100 \%$ more frequent in spoken discourse (Shin \& Nation, 2008). Together, the two studies support the conclusion that relatively few collocations are likely to be encountered frequently in written text. This makes researching incidental learning of collocations problematic unless texts are modified to include more encounters with target collocations.

A second reason for the lack of research on incidental learning of collocation is that studies of vocabulary learning have almost exclusively focused on learning form and meaning (the ability to link form to meaning rather than knowing both form and meaning). However, measuring knowledge of the form and meaning of collocations is not as straightforward as it is for single-word items and presents design problems for researchers. The transparency of the form and meaning of collocations can vary from highly transparent collocations to semantically opaque collocations. Although the greatest proportion of collocations is semantically transparent, the degree of transparency may vary from person to person and between learners of different language backgrounds. A problem also arises because measuring knowledge of form and meaning for transparent collocations is likely to be a function of knowledge of the form and meaning of the individual words in the collocation. For example, if you know the form and meaning of play and football then you should know the form and meaning of play football. This means that to measure incidental learning of transparent collocations, the collocations need to be made up of unknown words. However, such collocations are likely to occur so infrequently that it is not feasible to measure incidental learning within a short period of time without modifying materials. There is a similar problem with using semantically opaque collocations as the target items. Grant (2005) found that there are very few (only 103) semantically opaque multiword items (labeled core idioms in her study) in English and none of them occur frequently enough to be included in a list of the most frequent 5,000 single and multiword items. Thus, measuring 
incidental learning of collocations in the same way as single-word items with tests measuring meaning is problematic; the meanings of the most frequent collocations are likely to be transparent while the collocations that have less transparent meanings are infrequent.

Although form and meaning is an important aspect of knowledge of collocation, it is not the only one. Nation and Webb (2011) listed nine aspects of knowledge of multiword units, each of which is applied to collocation in Table 1.

Along with linking the form of a collocation to its meaning, knowledge of the form or composition of a collocation is also critical to productive language use. Knowledge of form allows learners to improve levels of accuracy and fluency (Wray, 2000), while a lack of knowledge of form may result in errors in speech and writing. For example, although strong and powerful have similar meanings, engine is a collocate of powerful but not strong while tea is a collocate of strong but not powerful. It is unusual word combinations such as powerful tea and strong engine that often distinguish L2 output from L1 output (Nesselhauf, 2003). Ideally then, studies investigating knowledge of collocation would first measure knowledge of form to determine whether learners can recognize and produce the forms of collocations and then measure receptive and productive knowledge of form and meaning to determine whether they can link the forms of collocations to their meanings.

\section{The Importance of Frequency of Encounters in Incidental Lexical Learning}

Research has consistently shown that single-word items are learned incidentally through reading by both L1 learners (Jenkins et al., 1984; Nagy, Anderson, \& Herman, 1987; Nagy, Herman, \& Anderson, 1985; Shu, Anderson, \& Zhang, 1995) and L2 learners (Day, Omura, \& Hiramatsu, 1991; Dupuy \& Krashen, 1993; Hulstijn, 1992; Pitts, White, \& Krashen, 1989). One area of research on incidental vocabulary learning has examined the effects of repetition on learning; the more an unknown word is encountered in context, the more likely its form and meaning will be learned (Chen \& Truscott, 2010; Horst et al., 1998; Jenkins et al., 1984; Pigada \& Schmitt, 2006; Rott, 1999; Saragi et al., 1978; Waring \& Takaki, 2003; Webb, 2007). Rott (1999) found that six encounters may be enough to learn words. Horst et al. (1998) found that eight encounters may be necessary, and Waring and Takaki (2003) suggested that it may take more than 20 encounters to incidentally learn words. One reason why the number of encounters may vary is that more proficient learners may learn items after fewer encounters than less proficient learners (Zahar, Cobb, \& 
Table 1 What is involved in knowing collocations

\begin{tabular}{|c|c|c|c|}
\hline \multirow[t]{6}{*}{ Form } & \multirow[t]{2}{*}{ spoken } & $\mathrm{R}$ & What does the collocation sound like? \\
\hline & & $P$ & How is the collocation pronounced? \\
\hline & \multirow[t]{2}{*}{ written } & $\mathrm{R}$ & What does the collocation look like? \\
\hline & & $\mathrm{P}$ & $\begin{array}{l}\text { How is the collocation written and } \\
\text { spelled? }\end{array}$ \\
\hline & \multirow[t]{2}{*}{ word parts } & $\mathrm{R}$ & $\begin{array}{l}\text { What words are recognizable in this } \\
\text { collocation? }\end{array}$ \\
\hline & & $\mathrm{P}$ & $\begin{array}{l}\text { What words are needed to express the } \\
\text { meaning? }\end{array}$ \\
\hline \multirow[t]{6}{*}{ Meaning } & \multirow[t]{2}{*}{ form and meaning } & $\mathrm{R}$ & $\begin{array}{l}\text { What meaning does this collocation } \\
\text { signal? }\end{array}$ \\
\hline & & $\mathrm{P}$ & $\begin{array}{l}\text { What collocation can be used to express } \\
\text { this meaning? }\end{array}$ \\
\hline & \multirow[t]{2}{*}{ concept and referents } & $\mathrm{R}$ & What is included in the concept? \\
\hline & & $P$ & What items can the concept refer to? \\
\hline & \multirow[t]{2}{*}{ associations } & $\mathrm{R}$ & $\begin{array}{l}\text { What other words or collocations does } \\
\text { this make us think of? }\end{array}$ \\
\hline & & $\mathrm{P}$ & $\begin{array}{l}\text { What other words or collocations could } \\
\text { we use instead of this one? }\end{array}$ \\
\hline \multirow[t]{6}{*}{ Use } & \multirow[t]{2}{*}{ grammatical functions } & $\mathrm{R}$ & $\begin{array}{l}\text { In what patterns does the collocation } \\
\text { occur? }\end{array}$ \\
\hline & & $\mathrm{P}$ & $\begin{array}{l}\text { In what patterns must we use this } \\
\text { collocation? }\end{array}$ \\
\hline & \multirow[t]{2}{*}{ collocations } & $\mathrm{R}$ & $\begin{array}{l}\text { What words, collocations, or types of } \\
\text { collocations occur with this one? }\end{array}$ \\
\hline & & $\mathrm{P}$ & $\begin{array}{l}\text { What words, collocations, or types of } \\
\text { collocations must we use with this } \\
\text { one? }\end{array}$ \\
\hline & \multirow{2}{*}{$\begin{array}{l}\text { constraints on use } \\
\text { (register, frequency } \\
\text {...) }\end{array}$} & $\mathrm{R}$ & $\begin{array}{l}\text { Where, when, and how often would we } \\
\text { expect to meet this collocation? }\end{array}$ \\
\hline & & $\mathrm{P}$ & $\begin{array}{l}\text { Where, when, and how often can we use } \\
\text { this collocation? }\end{array}$ \\
\hline
\end{tabular}

Note. $\mathrm{R}=$ receptive; $\mathrm{P}=$ productive. (Adapted from Nation \& Webb, 2011, p. 190.)

Spada, 2001). A second reason is because some contexts provide a lot of useful information, some provide little information, and some provide misleading information about the meaning of words (Beck, McKeown, \& McCaslin, 1983). Differences between findings may be due to the amount of information in the contexts for each encounter, as well as the test format used. Webb (2008b) 
found that when learners encountered L2 words in contexts rated as more and less informative, the more informative contexts contributed to greater learning.

Mackin (1978) suggests that collocations are likely to be acquired incidentally in the same manner that the majority of single-word items are learned. Research has provided some indication that knowledge of collocation may be gained incidentally through reading. Webb (2007) tested L2 learners on their ability to recognize and produce acceptable collocates for nonsense words they encountered in either $1,3,5,7$, or 10 sentences. The results indicated that increased encounters with the nonsense words led to significantly greater collocational knowledge. However, the study examined repeated encounters with single-word items rather than collocations. Similar research investigating what is learned through repeated encounters with collocations remains to be done.

\section{The Present Study}

There are several reasons why research on incidental learning of collocation as a factor of frequency of encounters is needed. First, it increases our understanding of an underresearched dimension of vocabulary learning. Second, it may indicate the extent to which collocations need to be taught. Bahns and Eldaw (1993) argue that, because L2 learners' knowledge of single-word items is far greater than that of collocations, there is a need to explicitly teach collocation. Laufer $(2001,2003)$ also argues that explicit vocabulary learning may be most useful because it leads to greater gains in vocabulary knowledge than incidental learning and there is a lack of L2 input for many foreign language learners to make sizeable incidental vocabulary learning gains. Cobb's (2007) corpus-driven analysis of the potential for incidental vocabulary learning through extensive reading also raises doubts about the sufficiency of incidental encounters with unknown vocabulary in text for learning. On the other hand, several researchers have argued that time is simply insufficient to teach all the vocabulary necessary to communicate effectively and therefore that learning words incidentally from input is a necessary part of L2 vocabulary learning (Krashen, 1985, 1989; Nagy et al., 1985). Third, determining the number of encounters necessary to learn collocations incidentally will provide a guide to how materials can be designed to promote learning. Graded reading schemes are planned around numbers of headwords. The present study may inform how schemes could also be designed to include repeated encounters with collocations to optimize learning.

The present study seeks to contribute to knowledge in relation to each of these points by investigating the likelihood of incidental collocation learning 
as a factor of the frequency of target collocations encountered in a text. Specifically, the study was designed to investigate the number of encounters $(1,5$, $10,15)$ in a graded reader necessary to gain knowledge of the written form and to link the form and meaning of collocations, defined statistically as individual lexical items that regularly co-occur within a given span demonstrating a statistical strength of co-occurrence. Accordingly, the following research questions were posed:

1. Can collocations be learned incidentally through reading while listening to a modified graded reader?

2. How many encounters with collocations are needed to incidentally learn the written form of the collocations when reading while listening to a modified graded reader?

3. How many encounters with collocations are needed to incidentally learn the form and meaning of the collocations when reading while listening to a modified graded reader?

\section{Method}

\section{Participants}

The participants were 161 first- and second-year university students learning English as a foreign language (EFL) at three universities in Taiwan. All of the participants had formally studied English for a minimum of 6 years and had a minimum raw score of 27 out of 30 on the 2,000 word level of the Vocabulary Levels Test (Schmitt, Schmitt, \& Clapham, 2001). Their mean raw score was 28.38 , indicating that they had receptive knowledge of the most frequent 2,000 word families and should have little difficulty understanding all of the running words in the treatments. Each group of participants was made up of students from one of five different classes. The groups were randomly assigned to the different learning conditions.

\section{Design}

There were four experimental groups and one control group. Each experimental group read a modified graded reader while listening to a recording of the story. Although reading while listening is not most learners' normal way of reading, it ensured that the participants would read the text with sufficient time to complete the posttests. This approach was effectively applied in Horst et al.'s (1998) study, which examined the effects of repetition on single-word items. The availability of audio versions of many graded readers in recent years also provides ecological validity to this approach. For example, Tom Cobb's 
Compleat Lexical Tutor site (http://www.lextutor.ca/ra_read/graded/) has text and audio versions of 11 graded readers that are freely available to language learners. Reading while listening to graded readers has also been found to be an effective method of incidental vocabulary learning of single-word items. Brown, Waring, and Donkaewbua (2008) found that reading while listening to graded readers led to greater incidental vocabulary learning than through only reading the graded readers.

Four different versions of the graded reader were created. In each version, a set of 18 target collocations was encountered a different number of times. One native speaker of English recorded all four aural versions of the texts and no emphasis was placed on the collocations in the readings. Experimental Group 1 encountered each of the 18 collocations once within the graded reader, Experimental Group 5 encountered the set five times, Experimental Group 10 encountered the set 10 times, and Experimental Group 15 encountered the set 15 times. The control group did not read or listen to any version of the graded reader but was administered the pre- and posttests at the same intervals as the experimental groups.

One week before the treatment, all of the participants were administered the Vocabulary Levels Test (Schmitt et al., 2001) and a pretest measuring receptive knowledge of form of the target collocations. The participants were given as much time as they needed to complete the tests. In the experiment, which was conducted within a 100-minute class, each experimental group completed one treatment and the posttests. The posttests were handed out one at a time immediately after the treatments. The participants were unaware that they would be tested and had as much time as they needed to complete the tests.

\section{Time}

The time taken to read and listen to the graded readers varied between the groups because of the difference in text length between the different versions of the book. The amount of time per word in the different aural versions of the text ranged from 143 ( 1 encounter) to 176 (15 encounters) per minute. The aural versions of the texts were limited to a maximum of 40 minutes to ensure that there was sufficient time within the class period to read the text and complete the tests. Each version was pilot tested with non native speakers and found to be at an acceptable speed to read and understand the texts. The times and the text lengths are shown in Table 2.

\section{Target Collocations}

Eighteen collocations with a low degree of congruence (i.e., word-for-word overlap between L1 and L2 form and meaning) were selected for this 
Table 2 Time and number of tokens in the graded reader versions

\begin{tabular}{llc}
\hline Treatment & \multicolumn{1}{c}{ Time } & Tokens \\
\hline 1 encounter & 30 minutes and 44 seconds & 4,383 tokens \\
5 encounters & 34 minutes and 22 seconds & 5,394 tokens \\
10 encounters & 38 minutes and 8 seconds & 6,029 tokens \\
15 encounters & 38 minutes and 37 seconds & 6,798 tokens \\
\hline
\end{tabular}

experiment. They are shown together with their L1 translations and their $t$ scores (taken from the Bank of English) in Appendix S1 of the Supporting Information online. The $t$ scores there indicate the degree of strength of collocation; the higher the $t$ score, the greater the strength of collocation.

All collocations were relatively semantically opaque. For example, the three collocations face facts, blow nose, and read thoughts were translated as 面對事實 (face truth), 擤鼻涕 (clean nose), and 瞭解他人的想法 (understand other people's thinking), respectively. If the collocations had a high degree of overlap in translation equivalency, then it could be argued that the tests of form and meaning would have been measuring the link between form and meaning of the individual words rather than the ability to learn target word combinations. Nesselhauf (2003) found that the degree of congruence had the greatest impact on intralingual collocation difficulty; the greatest percentage of learner errors was for noncongruent collocations.

The node word in each collocation was a verb with a noun as the collocate. Verb-noun collocations were chosen because previous research has indicated that they cause difficulty for EFL learners (Chan \& Liou, 2005; Nesselhauf, 2003). All of the collocations were made up of high-frequency words from the General Service List (West, 1953) except for one item (grant), which is found in the most frequent 1,000 word families in Nation's (2004) BNC lists. The results of the Vocabulary Levels Test indicated that the participants were likely to have receptive knowledge of all of the individual words within the collocations.

\section{Treatments}

Each experimental group read while listening to a modified version of the Oxford Bookworms graded reader New Yorkers (Henry, Hedge, \& Bassett, 2000). New Yorkers is a 700-headword stage-2 graded reader that was chosen because it was at the appropriate level for the learners; the vocabulary load was minimal so they were likely to be familiar with all of the running words in the text. The reader is made up of five short stories. This allowed a range 
of collocations to be inserted throughout the stories. Because the addition of the text containing the collocations increased the text length, one of the five stories (A Walk in Amnesia) was not included. Appendix S2 in the Supporting Information online shows how many times each collocation was encountered in the four short stories included in the modified version of New Yorkers. The collocations were inserted at different points in the graded reader to try to keep the distribution similar between versions.

All of the running words that made up the added text were high-frequency words from Nation's (2004) first and second 1,000 word lists. These sentences were written to conform with the detail present in the story and no attempt was made to clarify the meanings of the collocations within the sentences. This is consistent with the approach taken with single-word items in the writing of graded readers. Some sentences may have provided more information that could be used to derive the meanings of the collocations than others. However, controlling the amount of information in each sentence was not considered necessary because the research examines the between-participants factor (learning of the sets of collocations) rather than the within-participants factor (learning the individual collocations). As an illustration, Appendix S3 in the Supporting Information online lists the 15 sentences for the target collocation break silence included in the version for Experimental Group 15. Ten of the added sentences for each target collocation included for Group 15 were included in the version for Group 10, five of each of those were included for Group 5, and one of those was included for Group 1. The distance between the node words and collocates varied within the texts as did the forms of the collocations. For example, broke the silence, break her silence, breaking the silence, broke his usual silence were all included for the collocation break silence. This reflects typical authentic encounters with grammatically variable collocations (Nation \& Webb, 2011), although clearly not with grammatically fixed collocations.

\section{Dependent Measures}

A pretest and four immediate posttests were created to measure incidental learning of collocation. The pretest measured receptive knowledge of written form and the posttests measured two aspects of collocational knowledge (written form, form and meaning) at two levels of sensitivity (receptive and productive knowledge). Measuring multiple aspects of collocational knowledge should provide a more accurate assessment of learning than measuring a single aspect, and measuring each aspect at two levels of sensitivity should help to show the extent to which each of those aspects are learned. Although it would have been 
useful to measure some of the other aspects of collocational knowledge shown in Table 1, the use of collocations made up of real words made this problematic. Tests of written form and form and meaning were created because these aspects of knowledge may have the greatest value to learners.

A pretest measuring receptive knowledge of form was used to measure the participants' knowledge of the target collocations. The pretest had a multiplechoice format; the node word of each collocation was presented and the participants needed to circle the correct collocate from four choices (three distracters and an "I don't know" option). All of the distracters were among the 2,000 most frequent words and were likely to be known by all of the participants. The three distracters consisted of words found in the graded reader and one item was a collocate for a different target collocation. Although each distracter may occasionally appear together with the nodes in context, none of the distracters were nearly as frequent as the correct answer. For example, there are 260 occurrences of the target collocation remember time in the BNC. In contrast, the distracter most frequently encountered with remember was room, which was encountered together with remember 18 times. $t$ scores also indicated that the relationship between node words and distracters was not statistically significant. The following examples are for the target collocations break silence and meet demand:
(1) break
a) desk
b) final
c) silence
d) light
e) I don't know
(2) meet
a) seat
b) demand
c) name
d) question
e) I don't know

The four posttests administered after the treatments measured productive knowledge of form, receptive knowledge of form, productive knowledge of form and meaning, and receptive knowledge of form and meaning. Originally, two scores were calculated for the productive tests. One score was for partial knowledge of written form and one score was for full knowledge of written form. Using scores for partial and full knowledge of written form may provide a more accurate assessment of the effects of the treatments on productive knowledge (Nation \& Webb, 2011; Webb, 2008a; Webb \& Kagimoto, 2009). However, the results showed that there was no statistically significant difference between the two scoring systems so only the results of the full scoring system are reported in this article. In this system, all of the target collocations had to be spelled correctly.

On the first posttest, which measured productive knowledge of form, the node words were given and the participants had to write the collocates. The participants were instructed to write the noun that had been encountered after 
the node words in the stories. Three examples with correct and incorrect answers were provided to demonstrate how to score correctly. For example, to score correctly in item (3) below, the participants had to write the target collocate time beside the node word remember:

(3) remember

The second posttest was a multiple-choice test measuring receptive knowledge of form that was identical to the pretest except that the items appeared in a different order. Presenting verbs as the cues in verb-noun collocations in this test and the productive test of form is likely to make the test more sensitive to learning than presenting nouns as the cues. ${ }^{2}$ This is because collocations may be more easily recognized when they are cued by the first word rather than by the second. For example, it may be easier to recognize the collocation meet demand when meet is the cue rather than demand because meet is the first word in the sequence. The verb may also be the more difficult part of the collocation to recognize because the noun is freely chosen, and the verb conventionally tied to the noun (Nesselhauf, 2005).

The third posttest measuring productive knowledge of form and meaning used a translation format in which the L1 meanings cued the responses. The aim of this test was to determine whether the participants incidentally learned the form and meaning of the collocations. Because there was a low degree of overlap between the L1 and L2 form and meaning of the collocations, this test required participants to recall the L2 forms that they had encountered rather than simply translate the L1 Chinese characters into L2 items. For instance, to score correctly in (4), the participants had to write the collocation meet demand beside its L1 translation, which transliterated into English is satisfy needs:

(4) 滿足需要

The fourth and final posttest measured receptive knowledge of form and meaning using a receptive translation format. In this test the L2 collocations were the cues and the participants needed to write the L1 meanings. For example, in (5), the participants had to write the meaning of meet demand in the blank:

(5) meet demand

To score correctly, responses needed to demonstrate knowledge of the meanings of the collocations rather than the meanings of the individual items. 
Because the participants were cued with the L1 meanings in the third posttest, there may have been a learning effect from it on this last test. However, because the learners were unaware of the potential to learn from the previous test format and because this fourth test measured the participant's ability to link the collocations with their L1 meanings rather than demonstrate that they knew the L1 meanings, the effect may have been small. To reduce the possibility of a learning effect, the order in which the collocations were listed varied between all four tests.

Although delayed tests were also administered for the receptive and productive tests of form, the results and feedback from participants indicated that these findings were not valid measures of incidental learning. Scores were significantly higher for two groups (5 and 10) on the first delayed posttest measuring productive knowledge of form than on the corresponding immediate posttest, despite the fact that the participants were not aware that they would be tested again. Scores were also significantly higher for the control group on the delayed receptive test. Although scores for some groups did follow more typical patterns of incidental learning and were significantly lower, several participants informally reported to one of the researchers that they had been interested in learning the collocations after the immediate posttests and had looked them up in dictionaries. Thus, the immediate posttests alerted the participants to the purpose of the study and this affected their learning to some degree. Any knowledge demonstrated on the delayed tests could therefore not be attributed solely to the treatments, and thus the results are not reported in this article.

\section{Analysis}

The outcome variables of interest were the pre- and posttest scores on the measure of receptive form, and the immediate posttest scores of productive form, productive form and meaning, and receptive form and meaning. Preliminary testing of distributional assumptions on these variables, as well as outliers and multicollinearity, were conducted, and no violations were noted. Hence, normal theory methods were deemed appropriate for the analysis of these data. Preand posttests of receptive form were compared using a paired $t$ test, because we had paired observations. Multivariate analysis of variance (MANOVA) was used to compare groups $(0,1,5,10$, and 15) with respect to the multivariate outcome of all four scores on the immediate posttest. Because the normality assumption fit these data, MANOVA was the appropriate statistical analysis technique in this case. 
Table 3 Descriptive statistics of collocational knowledge

\begin{tabular}{llccccr}
\hline & & Pretest & & \multicolumn{4}{c}{ Immediate Posttests } \\
\cline { 4 - 7 } Version & & $\begin{array}{c}\text { Receptive } \\
\text { form }\end{array}$ & $\begin{array}{c}\text { Productive } \\
\text { form }\end{array}$ & $\begin{array}{c}\text { Receptive } \\
\text { form }\end{array}$ & $\begin{array}{c}\text { Productive } \\
\text { meaning }\end{array}$ & $\begin{array}{r}\text { Receptive } \\
\text { meaning }\end{array}$ \\
\hline 0 & Mean & 6.53 & .60 & 7.27 & 5.03 & 9.70 \\
$(n=30)$ & SD & 1.93 & .62 & 1.74 & 2.17 & 2.76 \\
& Min-Max & $3-11$ & $0-2$ & $4-10$ & $1-9$ & $5-10$ \\
1 & Mean & 6.59 & 2.06 & 9.65 & 4.68 & 9.50 \\
$(n=34)$ & SD & 1.76 & 1.63 & 2.75 & 2.01 & 2.76 \\
& Min-Max & $4-11$ & $0-5$ & $4-15$ & $1-9$ & $2-15$ \\
5 & Mean & 6.76 & 2.18 & 10.42 & 5.82 & 10.39 \\
$(n=33)$ & SD & 3.00 & 2.27 & 3.72 & 2.96 & 3.46 \\
& Min-Max & $1-12$ & $0-9$ & $5-18$ & $0-13$ & $3-16$ \\
10 & Mean & 6.17 & 5.33 & 12.70 & 8.47 & 11.63 \\
$(n=30)$ & SD & 2.21 & 4.73 & 3.22 & 3.77 & 2.83 \\
& Min-Max & $2-11$ & $0-18$ & $4-18$ & $2-17$ & $5-17$ \\
15 & Mean & 7.21 & 9.97 & 15.45 & 13.15 & 14.73 \\
$(n=33)$ & SD & 1.11 & 4.22 & 2.58 & 3.19 & 2.27 \\
& Min-Max & $5-9$ & $2-18$ & $8-18$ & $7-18$ & $10-18$ \\
\hline
\end{tabular}

Note. The maximum score on all tests was 18 .

\section{Results}

The descriptive statistics (means, standard deviations, minimum and maximum scores, and number of participants) of collocational knowledge on the five dependent variables (receptive form pretest, productive form, receptive form, productive form and meaning, and receptive form and meaning) are reported in Table 3. The independent variable was version of the graded reader according to frequency of exposure (5 levels: 0, 1, 5, 10, and 15). To answer research question 1 and determine whether the form of collocations can be learned incidentally through reading while listening to a modified graded reader, paired samples $t$ tests were conducted for the pretest and posttest scores on the receptive test of collocation within each version. Table 4 shows that there were statistically significant increases across versions in the receptive collocation scores from pretest to posttest. The largest mean increase was 8.24 for version 15 with a 99\% confidence interval (CI.99) ranging from 9.43 to 7.05 , and the effect size was very large (Cohen's $d=4.15$ ), followed by version 10 with a $99 \%$ CI.99 from 7.83 to 5.24, and the effect size was very large (Cohen's $d=2.36$ ), too. Version 5 and Version 1 increased by 3.66 and 3.06, but the effect size of 
Table 4 Paired samples $t$-tests for receptive form pretest to receptive form posttest across versions

\begin{tabular}{|c|c|c|c|c|c|c|c|c|c|}
\hline \multirow[b]{3}{*}{ Version } & \multicolumn{9}{|c|}{ Paired Differences } \\
\hline & \multirow[b]{2}{*}{$M$} & \multirow[b]{2}{*}{$S D$} & \multirow[b]{2}{*}{ SEM } & \multicolumn{2}{|c|}{ CI. 99} & \multirow[b]{2}{*}{$t$} & \multirow[b]{2}{*}{$d f$} & \multirow[b]{2}{*}{$p^{*}$} & \multirow[b]{2}{*}{ Cohen's $d$} \\
\hline & & & & Lower & Upper & & & & \\
\hline 0 & -.73 & 1.23 & .23 & -1.35 & -.11 & -3.27 & 29 & .003 & .40 \\
\hline 1 & -3.06 & 2.85 & .49 & -4.39 & -1.72 & -6.26 & 33 & .000 & 1.33 \\
\hline 5 & -3.66 & 2.52 & .44 & -4.87 & -2.47 & -8.36 & 32 & .000 & 1.08 \\
\hline 10 & -6.53 & 2.57 & .47 & -7.83 & -5.24 & -13.93 & 29 & .000 & 2.36 \\
\hline 15 & -8.24 & 2.50 & .44 & -9.43 & -7.05 & -18.94 & 32 & .000 & 4.15 \\
\hline
\end{tabular}

Note. CI. $_{99}=99 \%$ Confidence Internals.

*two-tailed.

version 1 was slightly higher than version 5 due to the standard deviation of the pretest for version 5 being much wider. Although version 0 also demonstrated a statistically significant increase (.73), the effect size was small $(d=.40)$.

To answer research questions 2 and 3 , a one-way between-groups MANOVA was conducted to investigate version differences on learning the form and form and meaning of the collocations. There was a statistically significant difference between versions on the combined dependent variables, $F(20,502)=11.87, p$ $<.0001$; Wilks's Lambda $=.28$, partial eta squared $=.28$. When the results for the dependent variables were considered separately, all except the receptive collocation pretest reached a statistically significant difference with a large effect size. One-way analyses of variance and post hoc tests using a Bonferroni adjusted level of .01 were conducted on the dependent variables that were significant in the MANOVA (see Table 5). The results showed: (a) The mean scores of version 15 were significantly higher than any other version on all four tests, (b) no significant differences were found between version 1 and version 0 across the four tests, (c) the mean scores of version 10 were significantly higher than version 5 on the two productive tests, and (d) the scores for version 5 was significantly higher than versions 1 and 0 on the receptive test of form.

\section{Discussion}

In answer to the first research question, the results indicate that encountering collocations when reading while listening contributed to incidental learning of collocation. Each version of the text contributed to significant gains in receptive knowledge of form. A significant increase was also found for the control 
Table 5 Results of analyses of variance across tests

\begin{tabular}{|c|c|c|c|c|c|c|c|}
\hline & $S S$ & $d f$ & $M S$ & $F$ & $p^{*}$ & $\begin{array}{c}\text { Eta } \\
\text { Squared }\end{array}$ & Post hoc tests \\
\hline Productive form & 1812.87 & 4 & 453.22 & 47.41 & .000 & .55 & $\begin{array}{l}15>10,5,1,0 \\
10>5,1,0\end{array}$ \\
\hline Receptive form & 1230.07 & 4 & 307.52 & 36.89 & .000 & .49 & $\begin{aligned} 15 & >10,5,1,0 \\
10 & >1,0 \\
5 & >0\end{aligned}$ \\
\hline Productive meaning & 1628.35 & 4 & 407.09 & 48.95 & .000 & .56 & $\begin{array}{l}15>10,5,1,0 \\
10>5,1,0\end{array}$ \\
\hline Receptive meaning & 603.41 & 4 & 150.85 & 18.67 & .000 & .33 & $15>10,5,1,0$ \\
\hline
\end{tabular}

${ }^{*}$ Alpha level set at $p<.01$.

group, indicating that there may have been a learning effect from taking the pretest. However, the analysis showed that the 15, 10, and 5 encounter groups had significantly higher scores on the receptive test of form on the immediate posttest than the 1 encounter and control groups, indicating that multiple encounters with the collocations had a significant effect on learning. The analysis also showed a very large effect size when encountering the collocations in the texts in comparison to a small effect size for the control group.

In answer to the second research question, the results indicate that repetition had a significant effect on learning the form of collocations; as the number of encounters increased, the amount of knowledge gained increased. On the receptive test of collocation, the mean scores for version 1 increased by 3.06 words or $27 \%$ of the unknown items (calculated as correct responses for previously unknown items divided by total items minus correct responses on the pretest). The mean scores for version 5 increased by 3.66 collocations $(33 \%)$, and the mean scores for versions 10 and 15 increased by 6.53 (55\%) and 8.24 collocations (76\%), respectively. The analysis showed that Group 15 had significantly higher gains than all other groups; Group 10 had significantly higher gains than Groups 5, 1, and the control group; and Group 5 had a significantly higher gain than the control group. The difference between Group 5 and the control group indicates that 5 or more encounters with collocations may be necessary to incidentally learn the form of collocations.

The receptive collocation posttest scores also provide some indication of the extent to which the forms of collocations may be learned through repeated encounters in a single text. The percentage of correct responses for versions $1(27 \%)$ and $5(33 \%)$ indicate that, although learning occurred for both, more 
than 5 encounters is necessary for effective learning of form. The percentage of items learned (76\%) for Group 15 indicates that encountering collocations 15 times within a graded reader may be sufficient for learners to recognize the form of collocations.

The results of the productive test of form should be interpreted with caution because productive knowledge of form was not measured on the pretest. Multiple pretests were not administered because they may have given away the purpose of the study, eliminating the possibility of measuring incidental learning. However, the results of the productive test support the data from the receptive test. Version 15 (9.97) contributed to significantly higher scores than all of the other versions, and version 10 (5.33) contributed to significantly higher scores than version 5 (2.18), version 1 (2.06), and the control group $(0.60)$. The percentage of correct responses for Group 15 (9.97 out of 18, 55\%) indicates that greater than 15 encounters may often be necessary for effective learning of productive knowledge of form.

In answer to the third research question, the results indicate that repetition may have a significant effect on learning the form and meaning of collocations incidentally. The results of the tests of form and meaning should also be interpreted with caution due to the lack of pretests measuring prior knowledge of this aspect. However, the results followed a similar pattern as those for the tests of form, indicating that the participants who read and heard version 15 had significantly higher scores on both the productive and receptive tests of form and meaning than participants who read the other versions. The mean scores (out of a total possible score of 18) ranged from 4.68 (26\%) for Group 1 to $13.15(73 \%)$ for Group 15 on the productive test and from $9.50(53 \%)$ for Group 1 to 14.73 (82\%) for Group 15 on the receptive test. Scores were also significantly higher for Group $10(8.47,47 \%)$ than those in Groups 5, 1, and the control group on the productive test. The lower scores on the productive test of form and meaning in comparison to the receptive test of form and meaning demonstrate the increased difficulty of gaining productive knowledge of collocation. This is similar to results found in studies of single-word items (Webb, 2005, 2007, 2009a, 2009b).

The scores on the immediate posttests of form and meaning are high in comparison to Waring and Takaki's (2003) study of single-word items, which found that learners could only score correctly on a receptive translation test for $42 \%$ of items encountered more than 15 times. This may be due to four factors: (a) prior knowledge of the form and meaning of the items that made up the collocations, (b) prior knowledge of the form and meaning of some of the 
collocations, (c) learning through reading while listening rather than learning through only reading, and (d) a test order effect. We discuss each in turn.

First, knowledge of form and meaning of the items that make up collocations is likely to have a positive effect on learning the meaning of collocations unless these are semantically opaque. The collocations in this study tended to be without clearly transparent meanings. However, the degree to which the meaning of collocations is semantically transparent to individuals is likely to vary. Some collocations may be harder to derive than others but they can still be derived through knowledge of the individual items. For example, while the ease with which the meanings of pull strings, lose touch, and blow nose can be derived may vary, they can be figured out through knowledge of the meanings of the words that make up the collocations. According to Grant and Bauer (2004), this is what differentiates them from semantically opaque items such as red herring and beat it, which cannot be derived through knowledge of the single-word items. Presenting collocations in multiple contexts should also have aided the learning process considerably. Second, the scores on the receptive pretest indicate that the learners were likely to already know the form and meaning of some of the target collocations. This is likely to inflate the scores in comparison to Waring and Takaki's (2003) study which used nonsense words so that there was no prior knowledge of the single-word items. Third, Brown et al.'s (2008) findings indicated that reading while listening led to greater incidental vocabulary learning than reading. This is likely to be true for collocations as well as for single-word items. When collocations are heard, they are likely to be heard without pauses or hesitations between the items (Bybee, 2002). This may provide some indication of their form. In text, however, collocations may be broken up on a page, with one word at the end of one line and another on the next line, perhaps reducing the learning of collocational form. Fourth, the first two posttests provided the node words for all of the collocations, and the second posttest provided the collocates together with three distracters. Seeing the nodes and the possible collocates may have helped the participants recall the form of the collocations during the productive test of form and meaning, which they completed as the third posttest. Moreover, the translation format may have contributed to knowledge of the collocations because, although there was not a high degree of L1-L2 congruence for the target collocations, there was still some degree of overlap. The degree of L1L2 word-for-word overlap in the collocation is a factor in learning collocations (Nesselhauf, 2003). Measuring the form and meaning of collocations is difficult due to transparency of meaning and the degree of congruence. More accurate results might be found with noncongruent collocations made up of unknown 
words or nonsense words because this eliminates those factors. However, this will decrease the ecological validity of the study because learning collocation is more likely to occur as learners increase their depth of knowledge for known words.

The pedagogical implications of the present findings are worthy of consideration. The results suggest that if an approach were taken to include useful collocations in graded reading schemes, there may be little need to teach collocations explicitly for learners actively taking part in extensive reading programs. Graded reading schemes could add the inclusion of target collocations to the criteria for writing the stories. The selection of the target collocations might be based on the individual items that make up the collocations; each item should already be among the sets of words that make up the headword for a level so that the lexical load does not increase. The selection should also be based on the frequency level of the collocations in language so that learners are encountering the collocations that have the most value to them. Martinez and Schmitt (2012), Shin (2007), and Shin and Nation's (2008) research provides useful lists of high-frequency collocations that might be used as a starting point. The strength of co-occurrence using a measure such as mutual information may be the most effective criterion for selecting the collocations for EFL learners who do not receive much L2 input (Simpson-Vlach \& Ellis, 2010). An alternative approach to selecting collocations would be to choose useful collocations that are unlikely to be encountered often enough to be learned incidentally in discourse, as Boers and Lindstromberg (2009, p. 61) suggest. These researchers also recommend selecting collocations that are memorable and might thus lead to more efficient teaching. This approach may be effective for learners of English as a second language (ESL), who receive a great deal of L2 input.

It may also be useful for teachers to deliberately include target collocations in their classroom speech. Horst's (2009) analysis of 50 hours of three ESL teachers' speech showed that 20 new words were each encountered 10 or more times each day, indicating that teacher speech may make useful contributions to vocabulary learning. If teachers were to plan on including unknown collocations that were made up of known words in their speech, this may raise awareness of target collocations and deepen their students' knowledge of known words.

\section{Limitations and Directions for Future Research}

Several elements of the present design may be modified in future research in order to explore alternative methodological research options when investigating incidental collocational learning. First, it would be useful to partially replicate 
this study using collocations that are made up of nonsense words. Authentic collocations were used in this study because learning nonsense words provided no learning value to the participants. Using real collocations has greater ecological validity, but it presents design problems that limit the generalizability of the findings. Ideally, pretests should be administered for all four tests. However, this was problematic because it would have alerted participants to the purpose of the study and may have also contributed to learning. Using collocations that are likely to be unknown and are made up of nonsense words eliminates this problem because pretests are not needed.

A second aspect of the research design that could be improved upon is the measurement of form and meaning. The present study aimed to measure knowledge of form and meaning at two levels (receptive and productive). Although productive tests have particular significance for measuring knowledge of collocation because it is the use of collocations that leads to the most evident L2 errors, any L1 cues provided on productive tests may contribute to learning. If there is any overlap between the L1 and L2 form and meaning of the collocations, then study participants may use their L1 knowledge to answer the question rather than any knowledge gained through completing a treatment. In the future, it might be more effective to measure receptive knowledge at two levels using a translation format to measure a greater degree of knowledge and a multiple-choice test with distracters that are not closely related, to measure a smaller degree of knowledge.

Third, as one of the reviewers noted, the form of the collocations may have had an effect on learning. Lindstromberg and Boers (2008a, 2008b) found that learner awareness of the presence of alliteration or assonance made collocations more memorable than unpatterned collocations. In the present study, exactly one third of the target collocations either assonate (blow nose, buy time) or alliterate (cut corners, face facts, make mind, run risk). This may have had a positive effect on learning. It is not clear whether sound repetition such as alliteration, assonance, and rhyme in some collocations makes them easier to learn incidentally than unpatterned collocations. The use of reading while listening in the study rather than reading only may have made these patterns more noticeable and possibly enhanced learning. It would be useful to examine this in further research.

A last area that should be noted for future exploration of alternative methodological options relates to the fact that prior knowledge of the items that make up the collocations may have an effect on the amount of knowledge that is gained. In this study the collocations were made up of two known words. However, they could have been made up of two unknown words or an unknown word 
and a known word. Prior knowledge of the items that make up collocations may affect the extent to which the form and the meaning of collocations are learned. Barcroft (2006) found that the requirement to write target words while viewing a series of word picture pairs presented at 6-second intervals rather than simply viewing the picture pairs without writing and instead focusing on both form and meaning took away from the extent to which form and meaning were learned. Thus, it follows that focusing on deriving the meaning of unknown words that make up collocations may reduce the potential to learn the form of collocations. If collocations are made up of unknown words or known and unknown words, then the learner's attention may be focused more closely on deriving the meaning of the individual words or the meaning of the collocation than on the form of the collocation. Another possibility is that knowledge of both composition and form and meaning is gained to a lesser degree when the collocations are made up of unknown words. When collocations are made up of known words, the learner's attention may be focused on learning the composition to a greater degree because their attention is not diverted to learning other aspects of word knowledge. On the other hand, Boers and Lindstromberg (2009, pp. 46-47) suggest that multiword units made up of unknown words may result in greater learning than if they are made up of known words because learners are more likely to notice unknown words. These contradictory positions suggest that investigating the effects of prior knowledge of the items that make up collocations would be a useful follow-up to this study.

Future research can build upon and extend the present research insights so as to glean pedagogically relevant knowledge that can be applied to L2 vocabulary instruction. The results of the present study indicate that collocations can be learned incidentally through repeated encounters in context in the same way that single-word items are learned. The findings indicate that 15 encounters with collocations in a single text of around 5,000 words can lead to substantial gains. This figure is higher than the number of encounters that was found to be required to incidentally learn single-word items in several studies (Horst et al., 1998; Rott, 1999; Webb, 2007) but fewer than the 20 encounters that Waring and Takaki (2003) suggest may be needed. However, it is important to note that the frequency of the collocations in this study was contrived and did not represent authentic text. Real encounter rates are far less frequent and it may be that any knowledge gained through one encounter is forgotten before the next encounter. Also, in the EFL learning situation that provided the context for this study, there may not be sufficient L2 input to facilitate the incidental vocabulary learning necessary to attain a native-like vocabulary of single-word items (see, e.g., Cobb, 2007; Laufer, 2001, 2003; Webb \& Chang, 2012). Because there 
are relatively few high-frequency collocations (Martinez \& Schmitt, 2012; Shin \& Nation, 2008), the potential for learning most collocations incidentally is relatively small unless materials are designed to include collocations at rates far higher than in authentic discourse. We have argued that the present study and other research suggest useful directions for how materials may be designed to promote incidental learning of multiword items. However, further research in this area is needed.

A useful follow-up to this study would also be to investigate incidental learning of high-frequency collocations at typical encounter rates in authentic text to determine the extent to which collocations may be learned incidentally by L2 learners. It would also be useful to look at the degree to which collocations are encountered in different types of text. It may be that, while collocations are relatively infrequent within a corpus, they may be more frequent within an individual text of a reasonable length or related texts, in the same way that single-word items are (see, e.g., Hwang \& Nation, 1989; Rodgers \& Webb, 2011; Schmitt \& Carter, 2000; Sutarsyah, Nation, \& Kennedy, 1994). However, Boers and Lindstromberg's (2009) analysis of the first 120 pages of a novel indicated that this may not occur to the same degree for collocations. They found that most verb-noun collocations were only encountered once in those pages.

With limited time for explicitly teaching vocabulary, ways of deepening vocabulary knowledge that do not use up language learning time are very useful. If graded reading schemes were to include presentations with collocations among their criteria for design, it is likely that encounters with collocations would be distributed over a range of readers rather than a single reader. Examining the effects of repetition on incidental learning of collocation with encounters distributed over a number of graded readers would be a useful follow-up to this study. The results of this study suggest that research examining the incidental learning of collocation through teacher talk would also be useful. If teachers can plan to use a set of target collocations in their speech during a course, they may be able to broaden vocabulary learning goals to include incidental learning of both single- and multiword units. ${ }^{3}$

Finally, it would also be useful from a pedagogical perspective to investigate incidental learning of collocations that vary in semantic transparency to see how this affects learning. For learners of a new language, semantically opaque collocations are likely to be the most difficult type of multiword unit to learn followed by items that have both a figurative and literal meaning and semantically transparent collocations, in that order (Grant \& Bauer, 2004). The 
degree to which knowledge of form is gained incidentally for the different types of collocations remains to be explored.

\section{Conclusion}

The results of the present study indicate that collocations are learned incidentally through repeated encounters in context. The process of learning collocations incidentally may be similar to the process of learning single-word items. Gains in knowledge of collocation through a single encounter are likely to be small. However, the more often that unknown collocations are encountered, the more likely they are to be learned.

Revised version accepted 20 December 2011

\section{Notes}

1 For recent discussion of the difference between statistical and phraseological definitions see Liu (2010).

2 As one reviewer noted there is also justification for using the noun as the cue because the verb is often seen as the collocationally difficult part of the combination (Nesselhauf, 2005).

3 One reviewer noted that the planned inclusion of target collocations in teacher speech may lead to explicit teaching of collocation through highlighting the forms of the collocations, glossing their meanings, and checking whether they were understood.

\section{References}

Bahns, J., \& Eldaw, M. (1993). Should we teach EFL students collocations? System, 21, 101-114.

Barcroft, J. (2006). Can writing a word detract from learning it? More negative effects of forced output during vocabulary learning. Second Language Research, 22, 487-497.

Beck, I. L., McKeown, M. G., \& McCaslin, E. S. (1983). Vocabulary: All contexts are not created equal. Elementary School Journal, 83, 177-181.

Boers, F., Demecheleer, M., \& Eyckmans, J. (2004). Etymological elaboration as a strategy for learning figurative idioms. In P. Bogaards \& B. Laufer (Eds.), Vocabulary in a second language: Selection, acquisition and testing (pp. 53-78). Amsterdam: John Benjamins.

Boers, F., \& Lindstromberg, S. (2009). Optimizing a lexical approach to instructed second language acquisition. Basingstoke, UK: Palgrave Macmillan. 
Brown, R., Waring, R., \& Donkaewbua, S. (2008). Incidental vocabulary acquisition from reading, reading-while-listening, and listening to stories. Reading in a Foreign Language, 20, 136-163.

Bybee, J. L. (2002). Phonological evidence for exemplar storage of multiword sequences. Studies in Second Language Acquisition, 24, 215-221.

Chan, T. P., \& Liou, H. C. (2005). Effects of web-based concordancing instruction on EFL students' learning of verb-noun collocations. Computer Assisted Language Learning, 18, 231-251.

Chen, C., \& Truscott, J. (2010). The effects of repetition and L1 lexicalization on incidental vocabulary acquisition. Applied Linguistics, 31, 693-713.

Cobb, T. (2003). Analyzing late interlanguage with learner corpora: Quebec replications of three European studies. Canadian Modern Language Review, 59, 393-423.

Cobb, T. (2007). Computing the vocabulary demands of L2 reading. Language Learning \& Technology, 11(3), 38-63.

Day, R. R., Omura, C., \& Hiramatsu, M. (1991). Incidental EFL vocabulary learning and reading. Reading in a Foreign Language, 7, 541-551.

Dupuy, B., \& Krashen, S. D. (1993). Incidental vocabulary acquisition in French as a foreign language. Applied Language Learning, 4, 55-63.

Durrant, P., \& Schmitt, N. (2010). Adult learners' retention of collocations from exposure. Second Language Research, 28, 163-188.

Erman, B., \& Warren, B. (2000). The idiom principle and the open choice principle. Text, 20, 29-62.

Fernando, C. (1996). Idioms and idiomaticity. Oxford, UK: Oxford University Press.

Forsberg, F. (2010). Using conventional sequences in L2 French. International Review of Applied Linguistics, 48, 25-51.

Foster, P. (2001). Rules and routines: A consideration of their role in the task-based language production of native and non-native speakers. In M. Bygate, P. Skehan, \& M. Swain (Eds.), Researching pedagogic tasks: Second language learning, teaching, and testing (pp. 75-93). Harlow, UK: Longman.

Gabrys-Biskup, D. (1992). L1 influence on learners' renderings of English collocations. A Polish/German empirical study. In P. J. L. Arnaud \& H. Bejoint (Eds.), Vocabulary and applied linguistics (pp. 85-93). London: Macmillan.

Granger, S. (1998). Prefabricated patterns in advanced EFL writing: collocations and formulae. In A. P. Cowie (Ed.), Phraseology, theory, analysis and applications (pp. 145-160). Oxford, UK: Clarendon Press.

Grant, L. (2005). Frequency of "core idioms" in the British National Corpus (BNC). International Journal of Corpus Linguistics, 10, 429-451.

Grant, L., \& Bauer, L. (2004). Criteria for redefining idioms: Are we barking up the wrong tree? Applied Linguistics, 25, 38-61.

Greenbaum, S. (1974). Some verb-intensifier collocations in American and British English. American Speech, 49, 79-89. 
Halliday, M. A. K. (Ed.). (1966). Lexis as a linguistic level. London: Longman. Henry, O., Hedge, T., \& Bassett, J. (2000). New Yorkers: Short stories [Oxford Bookworms Library Stage 2]. Oxford, UK: Oxford University Press.

Hill, J. (2001). Revising priorities: From grammatical failure to collocational success. In M. Lewis (Ed.), Teaching collocation: Further developments in the lexical approach (pp. 47-69). Hove, UK: Language Teaching Publications.

Horst, M. (2009). Revisiting classrooms as lexical environments. In T. Fitzpatrick \& A. Barfield (Eds.), Lexical processing in second language learners (pp. 53-66). Bristol, UK: Multilingual Matters.

Horst, M., Cobb, T., \& Meara, P. (1998). Beyond A Clockwork Orange: Acquiring second language vocabulary through reading. Reading in a Foreign Language, 11, 207-223.

Hulstijn, J. H. (1992). Retention of inferred and given word meanings: Experiments in incidental vocabulary learning. In P. Arnaud \& H. Bejoint (Eds.), Vocabulary and applied linguistics (pp. 113-125). London: Macmillan.

Hunston, S. (2002). Corpora in applied linguistics. Cambridge, UK: Cambridge University Press.

Hunt, A., \& Beglar, D. (2005). A framework for developing EFL reading vocabulary. Reading in a Foreign Language, 17, 23-59.

Hussein, R. F. (1990). Collocations: The missing link in vocabulary acquisition amongst EFL learners. Papers and Studies in Contrastive Linguistics, 26, 123-136.

Hwang, K., \& Nation, I. S. P. (1989). Reducing the vocabulary load and encouraging vocabulary learning through reading newspapers. Reading in a Foreign Language, 6, 323-335.

Jenkins, J. R., Stein, M. L., \& Wysocki, K. (1984). Learning vocabulary through reading. American Educational Research Journal, 21, 767-787.

Kennedy, G. (2003). Amplifier collocations in the British National Corpus: Implications for English language teaching. TESOL Quarterly, 37, 467-487.

Krashen, S. (1985). The input hypothesis: Issues and implications. London: Longman.

Krashen, S. (1989). We acquire vocabulary and spelling by reading: Additional evidence for the input hypothesis. Modern Language Journal, 73, 440-464.

Laufer, B. (2001). Reading, word-focused activities and incidental vocabulary acquisition in a second language. Prospect, 16(3), 44-54.

Laufer, B. (2003).Vocabulary acquisition in a second language: Do learners really acquire most vocabulary by reading? Canadian Modern Language Review, 59, $565-585$.

Laufer, B., \& Girsai, N. (2008). Form-focused instruction in second language vocabulary learning: A case for contrastive analysis and translation. Applied Linguistics, 29, 694-716.

Lindstromberg, S., \& Boers, F. (2008a). Phonemic repetition and the learning of lexical chunks: The mnemonic power of assonance. System, 36, 423-436. 
Lindstromberg, S., \& Boers, F. (2008b). The mnemonic effect of noticing alliteration in lexical chunks. Applied Linguistics, 29, 200-222.

Liu, D. (2010). Going beyond patterns: Involving cognitive analysis in the learning of collocations. TESOL Quarterly, 44, 4-30.

Mackin, R. (1978). On collocations: Words shall be known by the company they keep. In P. Strevens (Ed.), In honour of A. S. Hornby (pp. 149-165). Oxford, UK: Oxford University Press.

Martinez, R., \& Schmitt, N. (2012). A phrasal expressions list. Applied Linguistics. doi: 10.1093/applin/ams010

McEnery, T., \& Wilson, A. (2001). Corpus linguistics: An introduction (2nd ed.). Edinburgh, UK: Edinburgh University Press.

Mel'cuk, I. (Ed.). (1998). Collocations and lexical functions. Oxford, UK: Clarendon Press.

Moon, R. (Ed.). (1997). Vocabulary connections: Multi-word items in English. Cambridge, UK: Cambridge University Press.

Moon, R. (1998). Fixed expressions and idioms in English. Oxford, UK: Oxford University Press.

Nagy, W. E., Anderson, R. C., \& Herman, P. A. (1987). Learning word meanings from context during normal reading. American Educational Research Journal, 24, 237-270.

Nagy, W. E., Herman, P. A., \& Anderson, R. C. (1985). Learning words from context. Reading Research Quarterly, 20, 233-253.

Nation, I. S. P. (2001). Learning vocabulary in another language. Cambridge, UK: Cambridge University Press.

Nation, I. S. P. (2004). A study of the most frequent word families in the British National Corpus. In P. Bogaards \& B. Laufer (Eds.), Vocabulary in a second language: Selection, acquisition, and testing (pp. 3-13). Amsterdam: John Benjamins.

Nation, I. S. P. (2008). Teaching vocabulary: Strategies and techniques. Boston: Heinle.

Nation, I.S.P., \& Webb, S. (2011). Researching and analyzing vocabulary. Boston: Heinle.

Nesselhauf, N. (2003). The use of collocations by advanced learners of English and some implications for teaching. Applied Linguistics, 24, 223-242.

Nesselhauf, N. (2005). Collocations in a learner corpus. Amsterdam: John Benjamins.

Partington, A. (1998). Patterns and meanings. Amsterdam: John Benjamins.

Pigada, M., \& Schmitt, N. (2006). Vocabulary acquisition from extensive reading: A case study. Reading in a Foreign Language, 18, 1-28.

Pitts, M., White, H., \& Krashen, S. D. (1989). Acquiring second language vocabulary through reading: A replication of the Clockwork Orange study using second language acquirers. Reading in a Foreign Language, 5, 271-276. 
Rodgers, M. P. H., \& Webb, S. (2011). Narrow viewing: The vocabulary in related television programs. TESOL Quarterly, 45, 689-717.

Rott, S. (1999). The effect of exposure frequency on intermediate language learners' incidental vocabulary acquisition through reading. Studies in Second Language Acquisition, 21, 589-619.

Saragi, T., Nation, I. S. P., \& Meister, G. F. (1978). Vocabulary learning and reading. System, 6, 72-78.

Schmitt, N. (2000). Vocabulary in language teaching. Cambridge, UK: Cambridge University Press.

Schmitt, N. (2008). Review article: Instructed second language vocabulary learning. Language Teaching Research, 12, 329-363.

Schmitt, N., \& Carter, R. (2000). The lexical advantages of narrow reading for second language learners. TESOL Journal, 9(1), 4-9.

Schmitt, N., Schmitt, D., \& Clapham, C. (2001). Developing and exploring the behaviour of two new versions of the Vocabulary Levels Test. Language Testing, 18, $55-88$.

Shin, D. (2007). The high frequency collocations of spoken and written English. English Teaching, 62(1), 199-218.

Shin, D., \& Nation, I. S. P. (2008). Beyond single words: The most frequent collocations in spoken English. ELT Journal, 64, 339-348.

Shu, H., Anderson, R. C., \& Zhang, Z. (1995). Incidental learning of word meanings while reading: A Chinese and American cross-cultural study. Reading Research Quarterly, 30, 76-95.

Simpson-Vlach, R., \& Ellis, N. C. (2010). An academic formulas list (AFL). Applied Linguistics, 31, 487-512.

Sinclair, J. (1991). Corpus, concordance, collocation. Oxford, UK: Oxford University Press.

Stubbs, M. (1995). Collocations and semantic profiles. Functions of Language, 2, 23-55.

Sun, Y. -C., \& Wang, L.-Y. (2003). Concordancers in the EFL classroom: Cognitive approaches and collocation difficulty. Computer Assisted Language Learning, 16, 83-94.

Sutarsyah, C., Nation, I. S. P., \& Kennedy, G. (1994). How useful is EAP vocabulary for ESP? A corpus based case study. RELC Journal, 25(2), 34-50.

Walker, I., \& Hulme, C. (1999). Concrete words are easier to recall than abstract words: Evidence for a semantic contribution to short-term serial recall. Journal of Experimental Psychology: Learning, Memory, and Cognition, 25, 1256-1271.

Waring, R., \& Takaki, M. (2003). At what rate do learners learn and retain new vocabulary from reading a graded reader? Reading in a Foreign Language, 15, $130-163$.

Webb, S. (2005). Receptive and productive vocabulary learning: The effects of reading and writing on word knowledge. Studies in Second Language Acquisition, 27, $33-52$. 
Webb, S. (2007). The effects of repetition on vocabulary knowledge. Applied Linguistics, 28, 46-65.

Webb, S. (2008a). Receptive and productive vocabulary size. Studies in Second Language Acquisition, 30, 79-95.

Webb, S. (2008b). The effects of context on incidental vocabulary learning. Reading in a Foreign Language, 20, 232-245.

Webb, S. (2009a). The effects of pre-learning vocabulary on reading comprehension and writing. Canadian Modern Language Review, 65, 441-470.

Webb, S. (2009b). The effects of receptive and productive learning of word pairs on vocabulary knowledge. RELC Journal, 40, 360-376.

Webb, S., \& Chang, C-S. A. (2012). Second language vocabulary growth. RELC Journal, 43, 113-126.

Webb, S., \& Kagimoto, E. (2009). The effects of vocabulary learning on collocation and meaning. TESOL Quarterly, 43, 55-77.

Webb, S., \& Kagimoto, E. (2011). Learning collocation: Do the number of collocates, position of the node word, and synonymy affect learning? Applied Linguistics, 32, 259-276.

West, M. (1953). A general service list of English words. London: Longman, Green.

Wouden, T. V. D. (1997). Negative contexts: Collocation, polarity and multiple negation. London: Routledge.

Wray, A. (2000). Formulaic sequences in second language teaching: Principle and practice. Applied Linguistics, 21, 463-489.

Zahar, R., Cobb, T., \& Spada, N. (2001). Acquiring vocabulary through reading: Effects of frequency and contextual richness. Canadian Modern Language Review, $57,541-572$.

\section{Supporting Information}

Additional Supporting Information may be found in the online version of this article at the publisher's website:

Appendix S1. Target collocations' $t$-scores and L1 meanings.

Appendix S2. Placement and number of each collocation within the four stories. Appendix S3. The 15 sentences for the target collocation break silence for Experimental Group 15. 